26 Montgomery SA, Montgomery DB, Jayanthi-Rani S, Roy DH, Shaw PJ, McAuley R. Maintenance therapy in repeat suicidal behaviour: a placebo controlled trial. Proceedings of 10th International Congress for Suicide Prevention and Crisis Intervention; 1979; Ottawa: 227-9.

27 Linehan MM, Armstrong HE, Suarez A, Allmari D, Heard HL. Cognitivebehavioral treatment of chronically parasuicidal borderline patients. Arch Gen Psychiatry 1991:48:1060-4.

28 Torhorst A, Möller HJ, Bürk F, Kurz A, Wächtler C, Lauter H. The psychiatric management of parasuicide patients: a controlled clinical stud comparing different strategies of outpatient treatment. Crisis 1987;8:53-61.

29 Patsiokas AT, Clum GA. Effects of psychotherapeutic strategies in the treatment of suicide attempters. Psychotherapy 1985;22:281-90.

30 Gibbons JS, Butler J, Urwin P, Gibbons JL. Evaluation of a social work service for self-poisoning patients. Br J Psychiatry 1978;133:111-8.

31 Hawton K, McKeown S, Day A, Martin P, O'Connor M, Yule J. Evaluation of out-patient counselling compared with general practitioner care following overdoses. Psychol Med 1987;17:751-61.

32 Salkovskis PM, Atha C, Storer D. Cognitive-behavioural problem solving in the treatment of patients who repeatedly attempt suicide: a controlled trial. Br J Psychiatry 1990;157:871-6.

33 McLeavey BC, Daly RJ, Ludgate JW, Murray CM. Interpersonal problemsolving skills training in the treatment of self-poisoning patients. Suicide Life Threatening Behav 1994;24:382-94.

34 D'Zurilla TJ, Godfried MR. Problem solving and behaviour modification. JAbnorm Psychol 1971;78:107-26.

35 Hawton K, Catalan J. Attempted suicide: a practical guide to its nature and management. Oxford: Oxford University Press, 1982.

36 Chowdhury N, Hicks RC, Kreitman N. Evaluation of an after-care service for parasuicide (attempted suicide) patients. Soc Psychiatry 1973;8:67-81.

37 Welu TC. A follow-up program for suicide attempters: evaluation of effectiveness. Suicide Life Threatening Behav 1977;7:17-30.

38 Hawton K, Bancroft J, Catalan J, Kingston B, Stedeford A, Welch N Domiciliary and out-patient treatment of self-poisoning patients by medical and non-medical staff. Psychol Med 1981;11:169-77.

39 Allard R, Marshall M, Plante MC. Intensive follow-up does not decrease the risk of repeat suicide attempts. Suicide Life Threatening Behav 1992;22:303-14.
40 Van Heeringen CV, Jannes S, Buylaert H, Hendrick H, de Bacquer D, van Remoortel J. The management of non-compliance with referral to out-patient after-care among attempted suicide patients: a controlled intervention study. Psychol Med 1995;25:963-70.

41 Van der Sande R, van Rooijen E, Buskens E, Allart E, Hawton K, van der Graaf Y, et al. Intensive in-patient and community intervention versus routine care after attempted suicide: a randomised controlled intervention. Br J Psychiatry 1997;171:35-41

42 Liberman RP, Eckman T. Behavior therapy vs. insight-oriented therapy for repeated suicide attempters. Arch Gen Psychiatry 1981;38:1126-30.

43 Waterhouse J, Platt S. General hospital admission in the management of parasuicide: a randomised controlled trial. Br J Psychiatry 1990;156: 236-42.

44 Montgomery SA, Roy D, Montgomery DB. The prevention of recurrent suicidal acts. Br J Clin Pharmacol 1983;15:183-8S.

45 Torhorst A, Möller HJ, Kurz A, Schmid-Bode KW, Lauter H. Comparing a 3-month and a 12-month-outpatient aftercare program for parasuicide repeaters. In: Möller HJ, Schmidtke A, Welz R, eds. Current issues of suicidology. Berlin: Springer-Verlag, 1988:419-24.

46 Linehan MM, Heard HL, Armstrong HE. Naturalistic follow-up of a behavioral treatment for chronically parasuicidal borderline patients. Arch Gen Psychiatry 1993;50:971-4.

47 Hawton K, Fagg J. Deliberate self-poisoning and self-injury in adolescents: a study of characteristics and trends in Oxford, 1976-89. $\mathrm{Br} J$ Psychiatry 1992;161:816-23.

48 Pocock SJ. Clinical trials: a practical approach. Chichester: Wiley, 1983.

49 Light RJ, Pillemer DB. Summing up: the science of reviewing research. Cambridge, Massachusetts: Harvard University Press, 1984.

50 Hawton K, Kirk J. Problem-solving. In: Hawton K, Salkovskis P, Kirk J Clark DM, eds. Cognitive behaviour therapy for psychiatric problems: a practical guide. Oxford: Oxford University Press, 1989:406-26.

51 Linehan MM. Cognitive behavioral treatment of borderline personality disorder. New York: Guilford, 1993.

(Accepted 27 April 1998)

\title{
An epidemiological needs assessment of carotid endarterectomy in an English health region. Is the need being met?
}

\author{
G Ferris, P Roderick, A Smithies, S George, J Gabbay, N Couper, A Chant
}

\begin{abstract}
Objective: To compare the level of provision of carotid endarterectomy (an intervention of proved efficacy for prevention of stroke in patients with symptomatic high grade carotid artery stenosis) with estimates of need.

Design: Comparison of regional, district, and age-sex specific operation rates derived from hospital episode statistics with estimates of need based on demographic and epidemiological data; interviews with regional vascular surgeons and a joint provider-purchaser workshop to discuss implications. Setting: Former Wessex Regional Health Authority, 1991-2 to 1995-6.

Subjects: All residents covered by Wessex region treated for carotid artery reconstruction.

Main outcome measures: Regional, district, and age-sex operation rates as three year average 1993-6 (use) compared with respective estimates of need for carotid endarterectomy among those who presented with symptomatic carotid disease-transient ischaemic attack or minor stroke.

Results: The operation rate more than doubled between 1991-2 and 1995-6, from 35 to 89 per million population, compared with an estimated level of need in the region's general population of 153 per million population (transient ischaemic attack 77 , minor stroke 76 ). The ratio of use to need was 0.47
\end{abstract}

(95\% confidence interval 0.4 to 0.54 ); district ratios were $0.28(0.19-0.38)$ to 0.81 (0.62 to 1.06$)$. The annual use:need ratio rose over the three years 1993-6 from 0.38 to 0.59 . Use:need ratios were lower in elderly and female patients. Providers were keen to develop guidelines for referral and to increase access to diagnostic facilities; purchasers were more reluctant, given the limited impact of this intervention on the incidence of stroke and the relatively high cost of the operation.

Conclusion: Although treatment rates increased in Wessex there is still unmet need. Further research is needed to determine the referral pathways of patients with symptomatic carotid disease for diagnosis and operation and to evaluate strategies to improve access to diagnostic facilities.

\section{Introduction}

Stroke is the third commonest cause of death in the United Kingdom and the commonest cause of physical disability. ${ }^{1}$ Each year 64000 deaths (12\% of all deaths) are attributed to stroke. ${ }^{1}$ Treating and managing patients who have had a stroke is estimated to consume about $4.0 \%$ of NHS resources. ${ }^{2}$

Carotid endarterectomy (the removal of atherosclerotic lesions from the inner wall of the common carotid artery extending up to the internal carotid artery) has a small but significant part to play in
Wessex Institute for Health Research and Development, University of Southampton, Southampton General Hospital, Southampton SO16 6YD

G Ferris, research fellow P Roderick, senior lecturer A Smithies, research fellow S George, senior lecturer J Gabbay, professor

N Couper, research fellow Department of Vascular Surgery, Southampton University Hospitals' Trust, Southampton SO16 6YD

A Chant,

consultant vascular surgeon

continued over

BMJ 1998;317:447-51 
Correspondence to: Dr P Roderick, Wessex Institute for Health Research and Development Mail point 805 , Level B, South Academic Block, Southampton General Hospital, Southampton SO16 6YD pjr@soton.ac.uk preventing disabling stroke. ${ }^{23}$ Two randomised controlled trials-the North American symptomatic carotid endarterectomy trial and the European carotid surgery trial-showed the efficacy of carotid endarterectomy in preventing strokes in symptomatic patients (those with transient ischaemic attacks, amaurosis fugax, and minor stroke) with over $70 \%$ stenosis of the ipsilateral carotid artery. ${ }^{45}$ The number needed to treat to prevent one stroke is estimated at 7-10 patients over a two to three year follow up. ${ }^{45}$

In 1992 the Association of British Neurologists published guidelines recommending that, irrespective of age, all reasonably fit patients with a transient ischaemic attack, amaurosis fugax, or minor ischaemic strokes in the carotid artery territory who have made a good recovery within six months, should be investigated for carotid stenosis and other risks. ${ }^{6}$

Estimates suggest that if carotid endarterectomy were carried out on all eligible patients with transient ischaemic attack in England, the annual incidence of first ever strokes would decrease by $0.2-0.5 \%{ }^{3}{ }^{7}$ No estimates of the impact on minor strokes are available.

We compared the rate of carotid endarterectomy with estimated levels of need among patients who had presented to the NHS with symptomatic disease. We present information on the ratio of use to need overall, by district, and by age and sex, and we include the views expressed by regional vascular surgeons and purchasers. We discuss the implications for stroke prevention and for implementation of research evidence.

\section{Methods}

Current rates for carotid endarterectomy were derived from routine returns of inpatient activity hospital episode statistics by using the Wessex "Postbox" system. This database system enables purchasers and providers to exchange information about episodes of inpatient care.

We extracted entries for all carotid artery reconstructions (L29, according to operations coding by the Office of Population Censuses and Surveys ${ }^{8}$ ) performed on all residents covered by the former Wessex Regional Health Authority for the financial years 1991-2 to 1995-6. To improve the validity of the

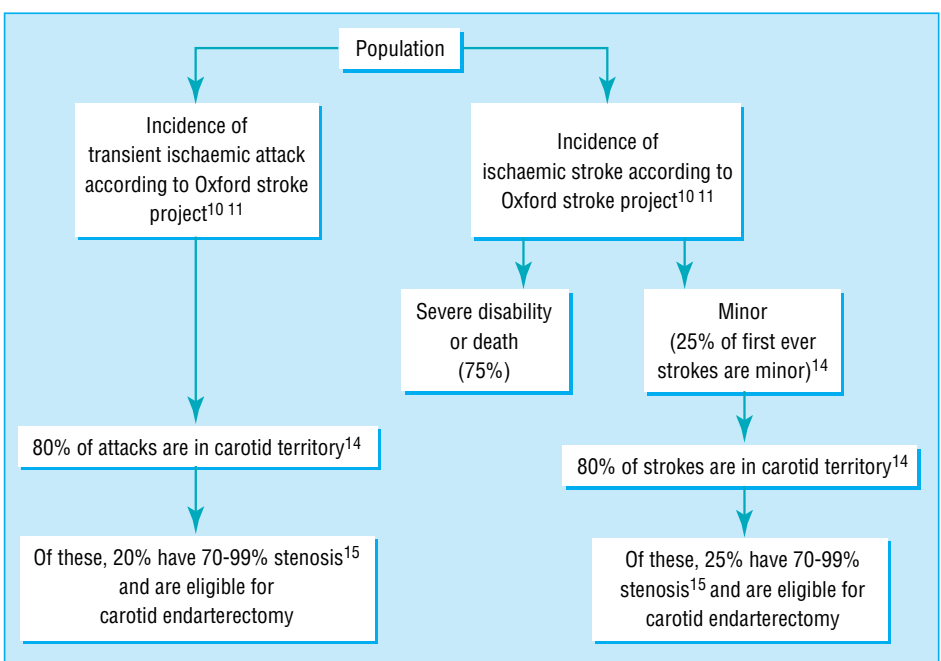

Fig 1 Process for estimating the number of cases of transient ischaemic attack and minor stroke eligible for carotid endarterectomy data we identified duplicates with cross checks on postcode, episode start and end dates, and patients' sex and date of birth. We judged records with the same postcode, date of birth, and sex as being valid or not depending on the episode dates in question. Thirty records were identified as duplicates and removed. We validated patients' ages against their date of birth. When missing, the age was calculated from the episode start date and the patient's date of birth.

The numbers of operations recorded per provider unit were confirmed during interviews with all the vascular surgeons performing carotid endarterectomy in Wessex and checked against the computer system run by surgeons in the largest surgical centre in Southampton. An estimated 30 operations were performed in the private sector in 1996 (A Chant, personal communication). For the years 1993-4 to $1995-6$ we calculated three year average age-sex treatment rates, and district standardised treatment ratios for the six health authorities using the direct method of standardisation with the whole region as a standard population. ${ }^{9}$

To estimate the level of need for carotid endarterectomy, we applied the data on the incidence of transient ischaemic attack and stroke from the Oxford community stroke project ${ }^{1011}$ to the age-sex population structure of the six district health authorities in Wessex. This assumes a similar incidence of stroke in the two regions (the age standardised mortality for stroke for those under 65 years (average for 1990-2) was 9.63 per 100000 in Oxford and 9.75 per 100000 in Wessex $^{12}$ ).

We then estimated the number of cases of transient ischaemic attack eligible for carotid endarterectomy according to various scenarios (fig 1). We used the age bands in the Oxford project. Age itself is not a bar to treatment, and during 1993-5, $8 \%$ of procedures in Wessex were in patients aged over 80 (2\% in patients over 85). We assumed the percentage of patients with transient ischaemic attack with stenosis in the carotid territory to be $80 \%{ }^{13}$ and of those with $70-99 \%$ stenosis to be $20 \%{ }^{14}$ on the basis of a hospital series of cases of transient ischaemic attack referred for carotid angiography. ${ }^{15}$ In the European carotid surgery trial 778 cases $(36 \%)$ had $70-99 \%$ stenosis. ${ }^{5}$ Patients not fitting the criteria were all excluded.

We used a similar process to produce a range of estimates for the number of eligible patients with minor stroke in Wessex (fig 1). Non-ischaemic strokes (estimated at $10-15 \%$ of all minor strokes ${ }^{2}$ ) were excluded by using the incidence of ischaemic strokes only from the Oxford project ${ }^{11}$ ). Major and fatal strokes, estimated at $75 \%$ of all first ever strokes, were excluded. We applied the same distribution and level of carotid stenosis proportions as for transient ischaemic attacks. Estimates for eligible patients with stroke included all patients with minor ischaemic stroke with 70-99\% stenosis.

We compared regional level, district level, and agesex specific estimates of need with their respective combined operation rates, giving a use:need ratio. Operation and use:need ratios are presented with 95\% confidence limits. ${ }^{16}$ For overall estimate of need we included all age groups.

All the findings presented here were discussed at a workshop with eight vascular surgeons (representing all but one of the region's units performing the operation), four regional purchasers, six other clinicians, one 
superintendant radiographer, and one provider manager. All vascular surgeons were also interviewed individually by one of us (AS) to explore the organisational and attitudinal background to carotid surgery.

\section{Results}

During 1995-6, 266 Wessex residents underwent a carotid artery reconstruction, a crude rate of 89 per million population and an overall increase of 63 operations on the previous financial year. The number of annual operations had increased substantially since 1991-2 (from 104 to 266). In 1995-6 the proportions of these operations performed by the providers in the region were $46 \%$ by Southampton, $19 \%$ by Royal United Bath, $12 \%$ by Bournemouth, $10 \%$ by Portsmouth, $5 \%$ by Winchester and $2 \%$ by North Hants $(6 \%$ were performed by non-Wessex providers). The age distribution for carotid endarterectomy (average for 1993-6) was 7\% for 0-54 years, $22 \%$ for $55-64,47 \%$ for $65-74,22 \%$ for $75-84$, and $2 \%$ for 85 years and older. Directly standardised district rates for carotid endarterectomy for 1993-6 showed significant variation (fig 2).

We estimated an incidence of transient ischaemic attack of 0.48 per 1000 people and a rate of first ever stroke of 1.9 per 1000 , according to the estimates derived from the Oxford data. ${ }^{10}{ }^{11}$ About 1429 transient ischaemic attacks and 5656 first ever strokes could be expected in Wessex annually, on the basis of the Office for National Statistics' mid-year population estimate for Wessex for 1994 (2.98 million). The estimates for

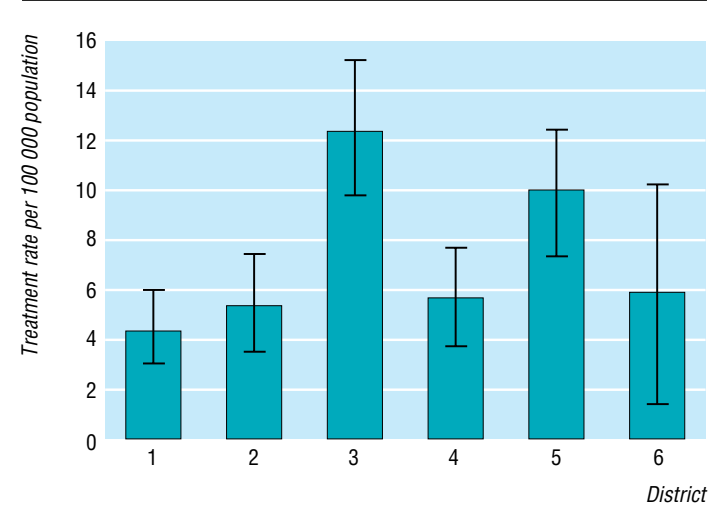

Fig 2 Directly standardised rates of carotid endarterectomy, by district for 1993-4 to 1995-6 (three year average)
Table 1 Estimates of need for carotid endarterectomy in patients in Wessex with transient ischaemic attack and minor stroke. Values are numbers of patients

\begin{tabular}{lrrrr} 
& \multicolumn{4}{c}{ Age (years) } \\
\cline { 2 - 5 } Event & $<\mathbf{6 5}$ & $<\mathbf{7 5}$ & $<\mathbf{8 5}$ & All ages \\
\hline Transient ischaemic attack & & & & \\
\hline Estimated incidence of transient ischaemic attack & 500 & 943 & 1329 & 1429 \\
\hline Carotid distribution (80\%) & 400 & 755 & 1063 & 1143 \\
\hline $70-99 \%$ stenosis (20\%) & 80 & 151 & 213 & 229 \\
\hline Rate (per million population) & 27 & 51 & 71 & 77 \\
\hline Stroke & & & & \\
\hline Incidence of ischaemic stroke & 1011 & 2687 & 4729 & 5656 \\
\hline Estimated incidence of minor stroke & 253 & 672 & 1182 & 1414 \\
\hline Carotid distribution (80\%) & 202 & 537 & 946 & 1131 \\
\hline $70-99 \%$ stenosis (20\%) & 40 & 107 & 189 & 226 \\
\hline Rate (per million population) & 14 & 36 & 64 & 76 \\
\hline
\end{tabular}

See results section for details of the data on which estimates are based.

patients eligible for carotid endarterectomy presenting with a transient ischaemic attack were 77 per million population (51 in those aged under 75) and with minor stroke 76 (36 in those aged under 75) (table 1). These levels varied depending on age groups included.

Comparison between the three year average provision of 213 operations (72 per million population) in 1993-6 and the expected level of provision for the same years (435 operations (153 per million population)) showed a use:need ratio of 0.47 (table 2). The annual use:need ratio rose from 0.38 to 0.59 over the three years 1993-4 to 1995-6.

There was substantial variation between districts in use:need ratios $(0.28$ to 0.81$)$. There was no direct relation between this ratio and a district's standardised mortality ratios for stroke.

Table 3 presents the rate of carotid endarterectomy by age and sex. Lower use:need ratios were present among female Wessex residents, and considerable variations were found between the different age groups, with those over 75 having the lowest use:need ratios.

At the workshop all participants agreed that carotid endarterectomy performed for appropriate indications and by experienced surgeons was an effective intervention and that it should be part of a comprehensive strategy for preventing and managing stroke. However, providers were more positive than purchasers about developing guidelines for referring patients for investigation of symptomatic carotid stenosis. Purchasers were more reluctant to tackle unmet need given the pressure on resources, the relatively high cost of carotid endarterectomy, ${ }^{17}$ and the limited impact it has on the incidence of stroke in the general population.

Table 2 Estimated number (rate per 100000 population) of patients with transient ischaemic attack or minor stroke eligible for carotid endarterectomy; average number (rate per 100000 population) of carotid endarterectomy operations; use:need ratios; and standardised mortality ratio for stroke. Results are by district health authority in Wessex for 1993-4 to 1995-6 (3 year average)

\begin{tabular}{|c|c|c|c|c|c|c|}
\hline District & $\begin{array}{c}\text { Transient } \\
\text { ischaemic } \\
\text { attack }\end{array}$ & Minor stroke & $\begin{array}{c}\text { Combined transient } \\
\text { ischaemic attack and } \\
\text { minor stroke }\end{array}$ & $\begin{array}{c}\text { Carotid } \\
\text { endarterectomy }\end{array}$ & $\begin{array}{l}\text { Use:need* ratio } \\
(95 \% \mathrm{CI})\end{array}$ & $\begin{array}{c}\text { Standardised } \\
\text { mortality ratio for } \\
\text { stroke } \dagger\end{array}$ \\
\hline District 1 & $63(9.4)$ & $64(9.6)$ & $128(19.0)$ & $34(5.1)$ & 0.28 (0.19 to 0.38$)$ & 83 \\
\hline District 2 & $39(7.3)$ & $38(7.1)$ & $77(14.4)$ & $27(5.1)$ & 0.35 (0.23 to 0.52$)$ & 100 \\
\hline District 3 & $40(7.6)$ & $39(7.5)$ & 79 (15.1) & $64(12.2)$ & 0.81 (0.62 to 1.06$)$ & 96 \\
\hline District 4 & $33(6.3)$ & $32(6.0)$ & $66(12.3)$ & $25(4.7)$ & $0.38(0.25$ to 0.58$)$ & 83 \\
\hline District 5 & $41(6.9)$ & $40(6.8)$ & $81(13.7)$ & $54(9.0)$ & 0.67 (0.50 to 0.90$)$ & 92 \\
\hline District 6 & $12(9.9)$ & $13(10.0)$ & $25(20.0)$ & $9(7.1)$ & $0.36(0.16$ to 0.88$)$ & 94 \\
\hline Whole of Wessex & $229(7.7)$ & $226(7.6)$ & $455(15.3)$ & $213(7.2)$ & $0.47(0.41$ to 0.54$)$ & \\
\hline
\end{tabular}

See methods section for details of the data on which estimates are based. The sum of the columns may not equal the given total owing to rounding.

${ }^{*}$ Need refers to the combined rate for patients with transient ischaemic attack or minor strokes eligible for carotid endarterectomy.

†1993 figures were taken from the 1994 Public Health Common Dataset (data for former Wessex region were not available). 
Table 3 Estimated number (rate per 100000 population) of patients with transient ischaemic attack or minor stroke eligible for carotid endarterectomy; average number (rate per 100000 population) of carotid endarterectomy operations; and use:need ratios. Results are for Wessex, 1993-4 to 1995-6 (3 year average), by age and sex

\begin{tabular}{lccccc} 
Age & $\begin{array}{c}\text { Transient } \\
\text { ischaemic } \\
\text { attack }\end{array}$ & Minor stroke & $\begin{array}{c}\text { Combined } \\
\text { transient } \\
\text { ischaemic attack } \\
\text { and minor stroke }\end{array}$ & $\begin{array}{c}\text { Carotid } \\
\text { endarterectomy }\end{array}$ & $\begin{array}{c}\text { Use:need }{ }^{*} \text { ratio } \\
\mathbf{9 9 5 \%} \text { Cl) }\end{array}$ \\
\hline Males: & & & & & \\
\hline $0-54$ & $11(1.0)$ & $6(0.5)$ & $16(1.5)$ & $10(0.9)$ & $0.62(0.29$ to 1.30$)$ \\
\hline $55-64$ & $28(19.5)$ & $16(11.2)$ & $45(30.7)$ & $31(21.4)$ & $0.70(0.47$ to 1.04$)$ \\
\hline $65-74$ & $50(38.9)$ & $36(28.4)$ & $86(67.3)$ & $68(53.1)$ & $0.79(0.61$ to 1.02$)$ \\
\hline $75-84$ & $32(48.2)$ & $38(54.4)$ & $70(106.6)$ & $28(42.8)$ & $0.40(0.27$ to 0.60$)$ \\
\hline$\geqslant 85$ & $2(11.2)$ & $11(66.8)$ & $13(78.0)$ & $2(12.1)$ & $0.15(0.40$ to 1.41$)$ \\
\hline All males & $122(8.3)$ & $107(7.3)$ & $229(15.7)$ & $139(9.5)$ & $0.61(0.51$ to 0.72$)$ \\
\hline Females: & & & & & \\
\hline $0-54$ & $9(0.9)$ & $6(0.5)$ & $15(1.4)$ & $5(0.5)$ & $0.33(0.11$ to 1.2$)$ \\
\hline $55-64$ & $15(10.1)$ & $10(6.8)$ & $25(16.9)$ & $17(16.9)$ & $0.67(0.38$ to 1.16$)$ \\
\hline $65-74$ & $22(14.4)$ & $31(19.6)$ & $53(34.0)$ & $31(34.0)$ & $0.58(0.40$ to 0.86$)$ \\
\hline $75-84$ & $39(36.6)$ & $43(40.8)$ & $82(77.4)$ & $20(77.4)$ & $0.24(0.15$ to 0.39$)$ \\
\hline$\geqslant 85$ & $21(45.9)$ & $26(57.6)$ & $47(103.5)$ & $1(103.5)$ & $0.02(0.001$ to 0.86$)$ \\
\hline All females & $107(7.0)$ & $116(7.7)$ & $223(14.7)$ & $74(14.5)$ & $0.33(0.26$ to 0.42$)$ \\
\hline
\end{tabular}

The sum of the columns may not equal the given total owing to rounding.

${ }^{*}$ Need refers to the combined rate for patients with transient ischaemic attack or minor strokes eligible for carotid endarterectomy.

\section{Discussion}

These data suggest that between 1991-2 and 1995-6 some patients in Wessex needing carotid endarterectomy did not receive it-despite a doubling in the number of operations over the three to four years since the Association of British Neurologists' guidelines were published. Operation rates in district health authorities varied considerably, suggesting inequity in access in relation to need; this was particularly marked in elderly and female patients.

\section{Methodological assumptions}

To address the discrepancy between the current and expected level of provision we need first to examine the robustness of the data and the assumptions of the estimates of need. Our estimate of need for patients with transient ischaemic attacks was based on the following premises: that all those with such attacks should be considered for surgery and therefore undergo diagnostic assessment; that only those with a carotid stenosis of $70-99 \%$ should be eligible for treatment; and that all ages should be included. These assumptions are based on evidence from the North American symptomatic carotid endarterectomy trial and the European carotid surgery trial; estimates from work by Hankey and Warlow ${ }^{13}{ }^{14}$; and data from the Oxford community stroke project. ${ }^{10}{ }^{11}$ However, this underestimates the true rate of transient ischaemic attack in the community (and hence the need for carotid endarterectomy); in the Oxford project a small subgroup of patients did not report their transient ischaemic attack to their doctor until after their first stroke, and another subgroup was not included as incident cases of transient ischaemic attack because the patients had a stroke during follow up. If combined, these would add another $27 \%$ to the overall incidence of transient ischaemic attack. Moreover, we have not considered patients with asymptomatic carotid disease who had severe stenosis; although the asymptomatic carotid atherosclerosis study ${ }^{18}$ suggests that these patients may benefit from surgery, the findings of the asymptomatic carotid surgery trial ${ }^{19}$ are awaited for clarification of the potential risk and benefits.

We used the same methods to calculate the number of eligible patients with minor ischaemic stroke. The same proportions for the distribution and level of carotid stenosis were applied as for transient ischaemic attack. We did not include cases from the Oxford project in which patients had an "uncertain" type of stroke, some of whom may have had ischaemic strokes. Such cases were predominantly in the very elderly age groups.

We could not ascertain from routine data whether current operations were being performed for appropriate indications, though vascular surgeons stated that the vast majority of patients were symptomatic and had over $70 \%$ stenosis of the appropriate internal carotid artery. If some of the operations performed were in symptomatic patients who had less than $70 \%$ stenosis or in asymptomatic patients, this would increase the level of unmet need for those with symptoms who had over $70 \%$ stenosis. Moreover, the study did not address directly the effectiveness of the services provided in terms of patient outcomes; nor could routine data indicate the appropriateness of surgery.

What of overestimation of need? We have not been able to adjust for comorbidity that may predicate against referral or consideration for surgery because of poor prognosis or unfitness for surgery. This may have partly accounted for the lower use:need ratios in older groups. Certainly comorbidity exclusion criteria had been applied, especially in the North American study. The vascular surgeons indicated that patients usually have other vascular disease and that this is not a reason to exclude them from the operation. Without further evidence to ascertain the true case mix of patients in the referral, eligibility, and treatment pathways, we cannot determine if we have overestimated unmet need in patients with minor stroke. The incidences of transient ischaemic attack and stroke were based on general practice populations in the Oxford region in the 1980s. Wessex and Oxford have comparable overall health status and stroke mortality. However, stroke incidence may have declined along with the fall in stroke mortality; if so, estimates of need will be too high.

A substantial underascertainment of NHS operations is unlikely as the surgeons confirmed the approximate number of operations. Our estimate of current provision excludes private operations, but anecdotal evidence from our vascular surgeons suggests that the number of private operations was fairly small (about 30 a year-less than $13 \%$ of the total). Inclusion of data on the number of private operations, even if double the suggested level, would not raise the level of current provision to the expected level.

\section{Explanations}

If our estimation of unmet need is accurate we needed to look at the wider issues to explain the gap between provision and need. Our workshop discussions indicated that the block was not with vascular surgeons but with referral for diagnostic assessment. This may have been due to a lack of awareness of the clinical indications for carotid endarterectomy, despite the availability of the national guidelines, leading to underreferral of patients with transient ischaemic attack or minor stroke for diagnostic assessment. Lack of access to duplex ultrasound scanning of the carotid artery may have contributed to 
this. The cost effectiveness of open access and "one stop" vascular clinics needs to be addressed, as these are potential strategies for increasing referrals and reducing delay in assessment. Routine data with breakdown of carotid endarterectomy by diagnosis of transient ischaemic attack or minor stroke were not available at this stage. An audit of vascular surgery cases would be needed to determine this, as the prime target groups of health professionals for referring patients with transient ischaemic attack are general practitioners and for referring patients with minor stroke are geriatricians, general physicians, and general practitioners.

We showed inequity by age and sex. Discussion with the vascular surgeons indicated that such inequity was not primarily due to variation in surgical practice. There may be implicit rationing by age, which may or may not reflect poor prognosis or reduced likely benefit because of associated comorbidity. Moreover, patient choice may be a factor, with older patients less likely to agree to surgery. Sanderson et al have shown how estimates of need for prostatectomy are sensitive to clinical severity and perceived impact of the condition, but also to patients' preferences about whether to undergo surgery, although the effect of age was inconsistent. ${ }^{20}$ Patients' preferences may partly explain the age and sex differences seen for carotid surgery.

Sex differences in treatment rates have been shown in other vascular interventions - notably, coronary artery bypass grafts. ${ }^{21}$ Further research is needed into the referral patterns of patients with symptomatic carotid disease to explore the reasons for the patterns of treatment seen.

The interdistrict analysis showed substantial variation in the use:need ratio. This could not be fully accounted for by comparison with stroke mortality ratios, as a proxy measure of stroke related need, which partly takes into account the socioeconomic characteristics of the population. The variation partly reflected the concentration of services - districts with a high use:need ratio tended to have one of the main provider sites. This is another example of demand being related to supply but not oversupply, as has often been implied.

\section{Conclusion}

This approach to determining use:need ratios is necessarily rather crude, relying on routine data and extrapolation from primary epidemiological studies. Nevertheless it has shown that despite robust evidence of the efficacy of carotid endarterectomy for patients with severe carotid stenosis, a considerable amount of unmet need and inequity of service provision at district level and by age-sex group still exists in an English health region. It will be important to see if operation rates continue to increase and to what extent this reduces inequity. Epidemiological data on the patterns of disease subgroups with the clinical indications for NHS interventions are important in understanding treatment patterns.

Even when general agreement exists about the strength of evidence for an intervention, getting it into practice will not necessarily be straightforward when it is costly and dependent on complex referral pathways for diagnosis and treatment.

We thank all the clinicians and purchasers who took part in the workshop and interviews.

Contributors: All authors were members of the project team that developed and implemented the review, and all contributed

\section{Key messages}

- Robust evidence exists that carotid endarterectomy is an effective intervention for patients with symptomatic carotid disease and who have $70-99 \%$ stenosis

- Operation rates increased in one English region after the production of national guidelines but were still half the estimate of population need

- The ratio of operation rates to estimated need varied considerably by district health authority and was lower in elderly and female patients

- Providers wanted to address this underprovision by improving referral and access to diagnostic ultrasound; purchasers emphasised the limited impact of carotid endarterectomy on the incidence of stroke in the general population

- Even when agreement exists about the strength of evidence for an intervention, getting it into practice may not be straightforward when it is costly and dependent on complex pathways for diagnosis and treatment

to the workshop and to the writing of the paper. AS and GF reviewed the literature, AS conducted the interviews, and GF undertook the data analysis. PR coordinated the writing of the paper.

Funding: The study was funded by South and West Research and Development Directorate.

Conflict of interest: None.

1 Secretary of State for Health. The health of the nation: a consultative document. London: HMSO, 1991. (Cm 1523.)

2 Wade DT. Stroke (acute cerebrovascular disease). In: Stevens A, Raftery J, eds. Health care needs assessment. Vol 1. Oxford: Radcliffe Medical Press, 1994:111-255.

3 Lambert M. Should carotid endarterectomy be purchased? Purchasers need a broader perspective $B M J$ 1995;310:317-8.

4 North American Symptomatic Carotid Endarterectomy Trial Collaborators. Beneficial effect of carotid endarterectomy in symptomatic patients with high grade carotid stenosis. N Engl J Med 1991;325:445-53.

5 European Carotid Surgery Trialists Collaborative Group. MRC European carotid surgery trial: interim results for symptomatic patients with severe $(70-90 \%)$ or with mild $(0-29 \%)$ carotid stenosis. Lancet 1991;337:1235-43.

6 Brown MM, Humphrey PRD. Carotid endarterectomy: recommendations for management of transient ischaemic attack and ischaemic stroke. $B M J$ 1992;305:1071-4.

7 Dennis M, Warlow C. Strategy for stroke. BMJ 1991;303:636-8.

8 Tabular list of the classification of surgical operations and procedures. 4 th revision. London: Office of Population Censuses and Surveys, 1991.

9 Rothman KJ. Modern epidemiology. Boston, Toronto: Little, Brown, 1986.

10 Dennis MS, Bamford JM, Sandercock PAG, Warlow CP. Incidence of transient ischaemic attacks in Oxfordshire, England. Stroke 1989;20:333-9.

11 Bamford J, Sandercock P, Dennis M, Warlow C, Jones L, McPherson K, et al. A prospective study of acute cerebrovascular disease in the community: the Oxfordshire Community Stroke Project 1981-86. community: the Oxfordshire Community Stroke Project 1981-86.
1. Methodology, demography and incident cases of first-ever stroke 1. Methodology, demography and incide
J Neurol Neurosurg Psych 1988;51:1373-80.

12 Department of Health, Institute of Public Health University of Surrey. Public health common dataset 1993 England. Vol 2. London: HMSO, 1994.

13 Hankey GJ. Impact of treatment of people with transient ischaemic attacks on stroke incidence and public health. Cerebrovasc Dis 1996;6(suppl 1):26-33.

14 Hankey GJ, Warlow CP. Symptomatic carotid ischaemic events: safest and most cost effective way of selecting patients for angiography, before carotid endarterectomy. BMJ 1990;300:1485-91.

15 Hankey GJ, Slattery JM, Warlow CJ. The prognosis of hospital-referred transient ischaemic attacks. J Neurol Neurosurg Psych 1991;54:793-802.

16 Clayton D, Hills M. Statistical models in epidemiology. Oxford: Oxford University Press, 1995.

17 Smithies A, Ferris G, Roderick P, Couper N, George S, Chant A, et al. Review of carotid endarterectomy in Wessex. Southampton: Wessex Institute for Health Research and Development, University of Southampton, 1997.

18 Executive Committee for the Asymptomatic Carotid Atherosclerosi Study. Endarterectomy for asymptomatic carotid artery stenosis. JAMA 1995;346:209-22.

19 Halliday AW. The asymptomatic carotid surgery trial (ACST) rationale and design. Eur J Vasc Surg 1994;8:703-10.

20 Sanderson CFB, Hunter DJW, Mckee CM, Black NA. Limitations of epidemiology based needs assessment: the case of prostatectomy. Med Care 1997;35:669-85.

21 Petticrew M, McKee M, Jones J. Coronary artery surgery: are women discriminated against? BMJ 1993;306:1164-6.

(Accepted 8 May 1998) 